University of Warwick institutional repository: http://go.warwick.ac.uk/wrap This paper is made available online in accordance with publisher policies. Please scroll down to view the document itself. Please refer to the repository record for this item and our policy information available from the repository home page for further information.

To see the final version of this paper please visit the publisher's website. Access to the published version may require a subscription.

Author(s): Samantha Johnson, Enid M Hennessy , Rebecca Smith Ms, Rebecca Trikic, Dieter Wolke and Neil Marlow

Article Title: Academic attainment and special educational needs in extremely preterm children at 11 years of age: the EPICure Study Year of publication: 2009

Link to published version: http://dx.doi.org/ 10.1136/adc.2008.152793

Publisher statement: None 


\section{Academic attainment and special educational needs in extremely preterm children at 11 years of age: the EPICure Study}

Samantha Johnson, Enid M Hennessy, Rebecca Smith, Ms, Rebecca Trikic, Dieter Wolke and Neil Marlow

Arch. Dis. Child. Fetal Neonatal Ed. published online 12 Mar 2009; doi:10.1136/adc.2008.152793

Updated information and services can be found at:

http://fn.bmj.com/cgi/content/abstract/adc.2008.152793v1

\section{These include:}

Rapid responses You can respond to this article at:

http://fn.bmj.com/cgi/eletter-submit/adc.2008.152793v1

Email alerting Receive free email alerts when new articles cite this article - sign up in the box at the service top right corner of the article

\section{Notes}

Online First contains unedited articles in manuscript form that have been peer reviewed and accepted for publication but have not yet appeared in the paper journal (edited, typeset versions may be posted when available prior to final publication). Online First articles are citable and establish publication priority; they are indexed by PubMed from initial publication. Citations to Online First articles must include the digital object identifier (DOIs) and date of initial publication.

To order reprints of this article go to:

http://journals.bmj.com/cgi/reprintform

To subscribe to Archives of Disease in Childhood - Fetal and Neonatal Edition go to:

http://journals.bmj.com/subscriptions/ 
The EPICure Study: Academic attainment and special educational needs in extremely preterm children at 11 years

Samantha Johnson, $P h D, C P$ sychol, Lecturer, Institute for Women's Health, UCL \& Research Psychologist, University of Nottingham.

Enid Hennessy, MSC. Senior Lecturer, Barts and The London School of Medicine and Dentistry, Queen Mary University of London.

Rebecca Smith, BSC (Hons), Research Psychologist, University of Nottingham.

Rebecca Trikic, BSC (Hons), Research Psychologist, University of Nottingham.

Dieter Wolke, Ph.D., Dipl-Psych, C.PSychol, Professor of Developmental Psychology and Individual Differences, University of Warwick

Neil Marlow, DM, FMedSci., Professor of Neonatal Medicine, Institute for Women's Health, UCL.

\section{Address for correspondence:}

Dr Samantha Johnson Lecturer in Academic Neonatology (Psychology)

Institute for Women's Health

86-96 Chenies Mews

London

WC1E 6HX

Email1: sam.johnson@nottingham.ac.uk

Email2: s.j.johnson@ucl.ac.uk

Tel: $\quad+44(0) 2076796051$

(www.epicure.ac.uk) 


\section{Abstract}

Aim. To assess academic attainment and special educational needs (SEN) in extremely preterm (EP) children in middle childhood.

Methods. Of 307 EP ( $\leq 25$ weeks) survivors born in the UK and Ireland in 1995, $219(71 \%)$ were re-assessed at 11 years, with a comparison group of 153 classmates born at term, using standardised tests of cognitive ability and academic attainment and teacher reports of school performance and special educational needs (SEN). Multiple imputation was used to correct for selective dropout.

Results. EP children had significantly lower scores than classmates for cognitive ability (-20 points; 95\%CI: $-23,-17)$, reading (-18 points; $-22,-15)$ and mathematics (-27 points; $-31,-23)$. Twenty-nine (13\%) EP children attended special school. In mainstream schools, 105 (57\%) EP children had SEN (OR: 10; 6, 18) and 103 (55\%) required SEN resource provision (OR: $10 ; 5,18$ ). Teachers rated $50 \%$ of EP children with attainment below the average range compared with $5 \%$ of classmates (OR: 18 ; $\mathrm{CI}: 8,41)$. EP children who are entered for mainstream education an academic year early due to preterm birth had similar academic attainment but required more SEN support (OR: $2 ; 1.1,3.8)$.

Conclusions. EP survivors remain at high risk for learning impairments and poor academic attainment in middle childhood. A significant proportion require full-time specialist education and over half of those attending mainstream schools require additional health or educational resources in order to access the national curriculum. The prevalence and impact of SEN is likely to increase as these children approach the transition to secondary school.

(249 words) 
Population-based studies have consistently shown that extremely preterm (EP) or extremely low birthweight (ELBW) children are at risk for functional disabilities later in life.(1-3) Cognitive impairment is the most prevalent disability at school age(1) and contributes to the excess of learning impairment and poor academic attainment in these populations, even among children without serious disability or cerebral palsy $(C P)(1,4-12)$. Although an underlying global cognitive deficit may account for much of the educational underachievement observed, differences in IQ scores do not account for all the learning difficulties in these children.(10, 13, 14)

Studies have shown that EP and ELBW children are more likely to require special school placement, repeat a school year (if applicable), have special educational needs (SEN) and to receive learning support than their term counterparts. $(6,7,15-$ 20) The prevalence of SEN and SEN resource provision provides an important measure of the totality of the functional deficit in this population. However, information regarding SEN resource utilisation in EP children is currently lacking.

We have studied educational outcomes in a whole population of EP children at 11 years of age. Firstly, we assessed general and specific academic attainment and the prevalence of learning impairment. Secondly, we investigated whether academic attainment and educational outcome is explained by a general cognitive deficit. Finally, we investigated educational outcomes for EP children entering compulsory education an academic year earlier than if they had been born at term.

\section{Participants}

The derivation of the study population has been described previously.(21) Of 307 survivors at 11 years, 11 (4\%) were resident outside the UK, the parents of $18(6 \%)$ refused consent and 57 (19\%) did not respond to invitations to participate. Thus, 219 (71\%) EP children were assessed at 11 years (Median age: 131m; range: 121m$145 \mathrm{~m})$.

At the previous 6-year follow-up, for each EP child in mainstream school we identified a classmate born at term matched for age, sex and ethnic group. Of 160 classmates evaluated at 6 years, 110 (69\%) were re-assessed at 11 years. We selected 43 new comparator children using the same methodology(1) to replace those now at a different school to the EP child or those declining participation. Thus 
a comparison group of 153 classmates was evaluated at 11 years of age (Median age: $131 \mathrm{~m}$; range $117 \mathrm{~m}-147 \mathrm{~m})$.

\section{Method}

Parents and children were given information leaflets and parents provided informed consent for their child's participation. Three psychologists blind to study group allocation assessed children in schools, or at home or hospital (13\%) if a school visit was not permitted. Study psychologists simultaneously scored the battery of standardised tests administered to non-study children prior to commencing EPICure study assessments and achieved excellent inter-rater reliability: $>95 \%$ agreement across test items for both standardised measures. The study was approved by the Southampton and South West Hampshire Research Ethics Committee.

\section{Measures}

Cognitive ability was assessed using the Kaufman-Assessment Battery for Children $(\mathrm{K}-\mathrm{ABC})(22)$. A Mental Processing Composite (MPC) score of 39 was allocated to 16 children who did not participate in testing with severe cognitive deficit. Two children who did not complete the K-ABC because of blindness and behavioural problems were classified with normal cognition based on teacher report. Academic attainment was assessed using the Wechsler Individual Achievement Test $2^{\text {nd }}$ Edition (WIAT-II ${ }^{\mathrm{UK}}$ ) for reading and maths.(23) A score of 39 was allocated to 18 children with severe cognitive deficit. Reading $(n=7)$ and maths $(n=4)$ scores were not substituted for children who failed to complete the test for other reasons (communication difficulties, behavioural issues, blindness). Given the secular drift in IQ scores over time, $(24,25)$ cognitive and learning impairment was classified into 4 categories according to conventional SD-banded cut-offs (none >-1SD; mild -1SD to -2SD; moderate -2SD to -3SD; severe <-3SD) using the mean and SD of the comparison group for each standardised test. A further test assessed intuitive mathematics (e.g. estimating numbers of dots, lengths of lines).(26, 27) Scores ranged 0-11 with higher scores indicating better performance.

Teachers in mainstream schools rated each child's performance in 7 subjects (English, maths, science, technology, geography, information technology (IT) and history). Scores were summed to yield a Total Academic Attainment Score (TAAS; 
range 1 to 5$)(28)$ which was used to classify performance below the average range (TAAS <2.5).

Teachers were asked to identify children with SEN, defined in the educational context as those with learning difficulties or disabilities that make it harder for them to learn or access education than most children of the same age, and were also asked to detail any SEN support the child received. The UK educational system adopts a 3stage approach to the provision of SEN resources that can culminate in a "Statement" - a legal document outlining a child's SEN and what provision must be made within the school and from external bodies. Statements are awarded to children in special schools and to those in mainstream schools with complex needs typically requiring multi-agency support. (Data relating to grade retention were not recorded as the UK adopts an age-based educational system in which school year repetition is rare.)

Parental socio-economic status (SES) was classified into four categories (SES-I: Professional/Managerial; SES-II: Intermediate; SES-III: Routine/Manual; SES-IV: Long-term unemployed/Never worked) using the UK National Statistics SocioEconomic Classification system.(29)

\section{Statistical analyses}

Data were double-entered, verified for accuracy and analysed using SPSS (SJ, EH).

Differences between groups in standardised test scores were analysed using independent samples t-tests or one-way analysis of variance as appropriate. Differences in standardised test scores between EP and comparison children were also adjusted for SES, and WIAT-II ${ }^{\mathrm{UK}}$ test scores were adjusted for general cognitive ability using multivariate regression. Estimation of the prevalence of serious cognitive (MPC <82) and learning (reading <74; maths <69) impairment and SEN in the whole cohort was done using multiple imputation to account for selective dropout.(30) Variables used to predict 11 year outcomes were those independently and statistically significantly $(p<0.05)$ associated with cognitive outcomes at discharge, 2.5 or 6 years.

\section{Results}

Loss to follow-up 
EP children lost to follow-up at 11 years $(n=88)$ were more likely to be of non-white ethnic origin, have unemployed parents, lower cognitive test scores and more frequent cognitive impairment at 2.5 and $6 y$ of age than those assessed $(n=219)$ (Supplemental Table s1).

\section{Cognitive ability}

EP children had significantly lower MPC scores than classmates (Table 1). Mean MPC was 82.9 (SD: 21.2) at 23w, 79.6 (SD: 20.8) at $24 w$ and 86.1 (SD: 15.3) at 25w. In the EP group boys had significantly lower scores than girls (-8 points; 95\%CI: -13 ,3). There was no sex difference among classmates. Excluding children with substituted scores, EP children had a mean MPC score 16.8 points $(-19,-14)$ lower than classmates. This group difference was -15.7 points in children for whom SES data were available ( $E P=169$; classmates=135), and adjustment for SES reduced this by 0.2 points (-15.5 points; $-18.2,-12.8)$. EP children also had lower scores than classmates for both sequential and simultaneous processing, the largest deficit being in simultaneous processing (Table 1). EP children were more likely to have a relative deficit in simultaneous compared with sequential processing than their classmates (72.; 3.2,16.1).(22)

\section{INSERT TABLE 1}

$40 \%$ of EP children had serious cognitive impairment (MPC <-2SD) compared with $1.3 \%$ classmates (OR:50; 12,206; Table 2). ${ }^{1}$ Among EP children, boys were more likely to have serious impairment than girls $(2.1 ; 1.2,3.7)$ but the prevalence of impairment was not significantly different for children born $23 / 24 w(45 \%)$ and $25 w$ $(36 \%)(1.48 ; 0.9,2.6)$. Using multiple imputation to correct for selective loss to follow-up of children with functional difficulties, the estimated proportion of EP children with serious cognitive impairment rose to $45 \%$ (95\% CI: 38,52$)$.

\section{INSERT TABLE 2}

\section{Academic attainment}

\footnotetext{
${ }^{1}$ Using $\mathrm{K}-\mathrm{ABC}$ test data, $13.7 \%$ (95\%CI: 9.5\%,19.1\%) of EP had serious cognitive impaiment compared with no classmates. Adjusting for loss to follow-up, the estimated proportion rose to $17.4 \%$ $(12.4 \%, 22.4 \%)$.
} 
EP children had significantly lower reading and maths scores than classmates (Table 1). EP boys had significantly lower scores than EP girls in reading $(-7$ points; $-1,-13)$ but not in maths (-4 points; $-1,10)$. No sex difference was found among classmates. Excluding children in whom severe cognitive impairment precluded test use $(n=17)$, EP children had a mean deficit of 15 points $(-18,-12)$ in reading and 25 points $(-28,-$ 21 ) in maths. Adjusting for SES in those with data available reduced the reading and maths deficits by only 0.5 and 0.3 points respectively. There were significant interaction effects of EP and MPC on both reading and maths with EP children having increasingly lower scores at lower MPC values than classmates. When adjusting for MPC, a significant effect of EP remained for maths $(-8.1 ;-11.3,-4.8)$ but not for reading $(-2.5 ;-5.5,0.5)$.

Sixty-four (30\%) EP children and 3 (2\%) classmates had serious impairment in reading (OR: 22; CI: 6.6,70) (Table 2 ). Serious impairment was marginally more common in EP boys than girls $(1.7 ; 0.9,3,0)$. Ninety-four (44\%) EP children and 2 (1.3\%) classmates had serious impairment in maths $(59 ; 14,243)$. Using multiple imputation to correct for selective loss to follow-up, the estimated proportion of EP children with serious impairment in reading rose to $33 \%(27,40)$ and to $50 \%(44$, 56) in maths.

Teacher questionnaires were returned for 200 (91\%) EP children and 146 (95\%) classmates. EP children in mainstream school had significantly poorer performance than classmates in all subjects rated, and $50 \%$ were classified with attainment below the average range compared with $5 \%$ of classmates (OR:18; 8,41 ).

\section{Special Educational Needs (SEN)}

SEN data were obtained for 215 (98\%) EP children and 152 (99\%) classmates. Twenty nine (13\%) EP children attended a special school and were more likely to be boys (OR: 3.6; CI: 1.5,8.6). Many more EP children than classmates had academic or behavioural SEN and utilised SEN provision, both overall and among those in mainstream schools only (Table 3 ). EP boys were more likely to have SEN and to utilise SEN provision than girls (Table 3). Among classmates, boys were more likely to have SEN $(3.8 ; 1.3,11.5)$ and marginally more likely to require SEN resources $(2.8$; $0.99,8.1)(p=0.052)$. Using multiple imputation to account for loss to follow-up, the 
estimated proportion of EP children with SEN and those utilising SEN support rose to $66 \%(60,72)$ and $64 \%(58,70)$

\section{INSERT TABLE 3}

Overall, EP children in mainstream schools utilised SEN resources more than classmates (OR 10; CI: 6, 18) (Figure 1). The services most commonly used by EP children compared with classmates were educational psychologists $(12 ; 2,95)$, oneto-one support $(10 ; 4,26)$ and small group provision $(9 ; 5,16)$. EP children in receipt of SEN provision had lower MPC scores than EP children who did not receive support (-15.9 points; $-19.1,-12.7)$. For those EP children requiring SEN provision, $57 \%$ utilised one resource, $24 \%$ used two, $11 \%$ used three and $8 \%$ utilised four or more types of resources. In contrast, only $12 \%$ of classmates required two forms of support.

\section{INSERT FIGURE 1}

There were more EP children in receipt of support in mainstream schools than were identified by teachers as having academic or behavioural SEN $(n=13): 10$ received minimal support (e.g., "Year 6 Booster classes", "programme for accelerated learning", "help with spelling", "lunchtime maths help"). Of the remaining 3 children, 1 had an Outreach teacher for hearing impairment, 1 a classroom assistant due to visual and hearing impairment and 1 an Occupational Therapist; all 3 were on the Local Authority Register for children with SEN. When the category for presence of SEN is extended to include these 13 children, 114 (61\%) EP children and 21 (14\%) classmates in mainstream schools had SEN (OR: 9.9; CI: 5.7, 17.1); this rises to $67 \%$ when children in special schools are included $(12.4 ; 7.2,21.3)$.

\section{Statements of SEN}

Seventy-two (34\%) EP children had a Statement of SEN compared with 1 (0.7\%) classmate (OR: $76 ; \mathrm{CI}: 10,552)$; this rose to $39 \%(33,45)$ using multiple imputation to estimate prevalence in the full cohort. In mainstream schools, $43(23 \%) \mathrm{EP}$ children had a statement $(46 ; 6,339)$ (Table 3$).^{2}$ Among EP children for whom Statement data were available, of those with MPC $<70(n=28) 22$ were in a special

\footnotetext{
${ }^{2}$ Results exclude Ireland. Scotland adopts a similar process to England and Wales and data are therefore included. The prevalence of statements in England \& Wales was not significantly different in the full cohort (35\% EP vs $0.8 \%$ classmates; OR: $70 ; \mathrm{Cl}: 10,512)$ and in mainstream schools (25\% EP vs $0.8 \%$ classmates; OR $43 ; 6,320)$.
} 
school and 7 in a mainstream school and all had a Statement; among the children with MPC $\geq 70$, having a Statement was independently associated with MPC, reading scores and CP. However, once maths and SES were included in the model both MPC and reading scores were no longer significant. After adjustment for each other, for those with MPC $\geq 70$ the OR for having a Statement for a ten point increase in maths score was $0.42(0.30,0.59)$, for having CP $7.1(1.8,27)$ and for SES Class IV 9.9 $(2.1,47)$.

\section{Early school entry}

A sub-group of 68 (36\%) EP children in mainstream school had dates of birth and gestational ages that would have placed them in an earlier academic year than if they had delivered at term ( $23 w n=4,22 \% ; 24 w n=24,40 \% ; 25 w n=40,36 \%$ ). There were no significant differences in standardised test scores for these children compared with the remainder of the EP cohort. However, more children entered for school a year early had SEN, statements and a greater proportion utilised SEN resources than the rest of the EP children (Table 4).

\section{INSERT TABLE 4}




\section{Discussion}

After initial anxieties regarding survival during the neonatal period, parents are increasingly concerned with how well their child is likely to get on at school and what kind of support may be needed for their child to realise his or her potential. We found that EP birth places children at high risk for cognitive and learning deficits affecting their schooling in middle childhood. Up to $44 \%$ had a serious impairment in the core subjects of reading and maths, and $50 \%$ had performance below the average range expected for their age across the full spectrum of subjects studied. EP children also had a thirteen times increased risk of SEN requiring additional learning support and were 77 times more likely to have an Educational Statement at 11 years of age.

Such a high prevalence of cognitive deficits in EP/ELBW survivors is a robust finding,(1, 2, 31-33). Although we have reported a higher prevalence than other population-based studies, we included only extremely immature births in whom a higher level of impairment would be expected given the gestational age-related gradient in cognitive function.(34-36) Furthermore, we classified impairment relative to the performance of the comparison group which yields higher rates but reflects reality as children are compared with the peers against whom they are judged in school. $(25,37)$

Comparable with our findings, other studies have shown that EP and ELBW survivors have poorer academic attainment than their term peers on teacher's ratings $(6,11)$ and standardised tests $(2,5,7,11,15)$, with rates of serious impairment up to $50 \% .(19,38)$ We also confirm maths as an area of specific difficulty in half of this population when loss to follow-up is accounted for. $(1,6,7,11)$ In contrast the deficits in reading scores were no longer evident after adjustment for general cognitive ability. $(10,11,14,31)$ Thus some learning difficulty associated with EP birth, particularly in language and reading, can be accounted for by a general cognitive impairment whilst mathematical difficulties appear to be a specific deficit. It has been suggested that this pattern of findings is largely indicative of a disruption to global brain development and imaging studies have provided confirmatory evidence of reduced cortical volume, size and complexity in preterm populations.(39, 40) The neuropsychological deficit appears to worse in simultaneous rather than sequential processing of complex information. $(1,14)$ Specific deficits in maths skills 
may be a result of more specific impairment of regional brain areas.(41) Such abilities are related to working memory, executive function, attentional control, perceptual and visuo-spatial skills, which are also selectively impaired in preterm populations. $(13,42,43)$ Interventions targeted at enhancing executive control and motor function may therefore attenuate the effects of prematurity on educational outcomes. Furthermore, behavioural and emotional problems $(44,45)$ may impact on scholastic performance in this population and may be amenable to intervention.

The impact of extreme prematurity is most evident in that two thirds have academic and behavioural SEN, compared with $11 \%$ of classmates and $24 \%$ in England.(46) The lower prevalence of special school placements than in other EP/ELBW populations $(19,32,38)$ reflects the UK policy for integration of children with SEN in mainstream schools. Indeed, $36 \%$ of EP children in mainstream school had serious functional neurodevelopmental disability.(47) SEN were not confined to those with severe disability as a further $21 \%$ of EP children in mainstream schools had SEN. The prevalence of Educational Statements was remarkably high in this population: 1/3 of all EP children, and almost 1/4 of EP children in mainstream schools, compared with 2.3\% in England.(46) The marked increase reflects the greater severity and complexity of learning support required, including physical and medical therapies, as indicated by the greater variety of special SEN services utilised in this population.

Most often SEN support comprised small group tuition or one-to-one support, but EP children also utilised services from a range of allied health professionals that were rarely accessed by classmates. EP children were also more likely to require support provided by external agencies and to require multiple support services impacting further upon the cost to schools and the local government for the education of these children. However, we have not investigated severity of SEN, and, whilst the vast majority of those with SEN are in receipt of some degree of provision, this support may be insufficient $(6,32)$ and some may also receive additional professional help at home that we have not recorded.

Schools in the UK adopt an age-based educational system. Local authorities vary in their policies for entry into nursery (preschool) and virtually all of this cohort will have started preschool in the academic year in which they reach 5 years. Entry to 
formal schooling is compulsory in the term after the child's $5^{\text {th }}$ birthday. As such, children will vary in age and length of schooling on admission. Children whose date of birth (DOB) and expected date of delivery (EDD) cross the cut-off date for school entry ( $1^{\text {st }}$ September) will ultimately be entered an academic year earlier than if they had been born at term. Concern is frequently expressed regarding educational outcomes for these children as the disadvantage already conferred by summer birth, due to age and length of preschool education $(48,49)$, may be compounded by premature school entry - a disparity that is never rectified throughout schooling.

When outcomes for EP children who would have entered mainstream school a year early were compared to the rest of the EP cohort there were no significant differences in mean age-standardised scores; similarly there were no significant differences between summer born and non-summer born classmates on these measures and neither did we find significant differences in WIAT-II ${ }^{\mathrm{UK}}$ raw scores or on non-standardised tests. However, EP children entered for school a year early had more SEN and Educational Statements. The additional support and resources utilised by these children may thus have contributed to their comparable academic attainment and if academic attainment is the outcome of concern then early school entry does not appear to disadvantage EP children. It may be advantageous to delay school entry, and to adopt admission rules based on corrected age, as these children may then require less SEN provision, with personal and social advantages of attenuating the impact of delayed cognitive and psychomotor development, emotional immaturity and social difficulties that are associated with EP birth. $(44,50)$ A preschool curriculum that emphasises language and social development, play and exploration may be more developmentally appropriate for EP children at this age. Although these data provide some preliminary results, more systematic investigation is required that is designed to study the impact of premature school entry.

We did not recruit comparison children for those in special schools and it may therefore be argued that impairment was overestimated in this study. However, we do not believe we have a high-achieving comparison group as classmates performed as would be expected in the normal population on standardised measures. We have also compared educational outcomes to current national statistics where possible. The small effects of SES on outcomes were expected as the selection of classmates typically adjusts for these factors. It is more likely that we have underestimated 
impairment in this population given the selective loss to follow-up of children with serious cognitive deficits and functional disability. Multiple imputation was used to account for selective dropout on educational outcomes. Using these techniques, the prevalence of cognitive impairment rose to $45 \%$ and the prevalence of those with SEN to $66 \%$.

In summary, we identified a high prevalence of learning deficits that impacted significantly upon the school performance and educational needs of EP children. By 11 years of age, around $60 \%$ of EP children require additional support in school and $1 / 3$ have an Educational Statement indicative of complex SEN. The impact of these impairments is likely to increase over time $(19,46,51)$ and existing difficulties may be exacerbated in secondary school when cognitive demands increase in parallel with progressively complex academic studies. The cost to society of extreme prematurity lies increasingly within the sphere of education(52) as these children grow older and approach the transition to secondary school. 


\section{References}

1. Marlow N, Wolke D, Bracewell MA, Samara M. Neurologic and developmental disability at six years of age after extremely preterm birth. New England Journal Of Medicine 2005;352(1):9-19.

2. Hack M, Taylor HG, Drotar D, Schluchter M, Cartar L, Andreias L, et al. Chronic conditions, functional limitations, and special health care needs of school-aged chldiren born with extremely low-birth-weight in the 1990s. Journal of the American Medical Association 2005;294:318-325.

3. Doyle L, Casalaz D. Outcome at 14 years of extremely low birthweight infants: a regional study. Archives of Disease in Childhood Fetal Neonatal Edition 2001;85:F159-164.

4. Botting N, Powls A, Cooke R, Marlow N. Cognitive and educational outcome of verylow-birthweight children in early adolescence. Developmental Medicine and Child Neurology 1998;40:652-660.

5. Saigal S, Szatmari P, Rosembaum P, Campbell D, King S. Cognitive ability and school performance of extremely low birth weight children and matched term control children at age 8 years: A regional study. The Journal of Pediatrics 1991;118(5):751-760.

6. Bowen J, Gibson F, Hand P. Educational outcome at 8 years for chidlren who were born extremely prematurely: A controlled study. Journal of Paediatrics \& Child Health 2002;38:438-444.

7. Saigal S, den Ouden L, Wolke D, Hoult L, Paneth N, Streiner DL, et al. School-age outcomes in children who were extremely low birth weight from four international populationbased cohorts. Pediatrics 2003;112(4):943-950.

8. Horwood LJ, Mogridge N, Darlow BA. Cognitive, educational, and behavioural outcomes at 7 to 8 years in a national very low birthweight cohort. Archives of Disease in Childhood Fetal Neonatal Edition 1998;79:12-20.

9. Grunau R, Whitfield MF, Fay TB. Psychosocial and academic characteristics of extremely low birth weight $(<800 \mathrm{~g})$ adolescents who are free of major impairment compared with term-born control subjects. Pediatrics 2004;114(6):e725-e732.

10. Wolke D, Samara M, Bracewell M, Marlow N. Specific language difficulties and school achievement in children born at 25 weeks of gestation or less. . Journal of Pediatrics 2008;152(2):256-262.

11. Anderson P, Doyle LW. Neurobehavioral outcomes of school-age children born extremely low birth weight or very preterm in the 1990s. JAMA-Journal Of The American Medical Association 2003;289(24):3264-3272.

12. Grunau RE, Whitfield MF, Davis C. Pattern of learning disabilities in children with extremely low birth weight and broadly average intelligence. Archives of Pediatric and Adolescent Medicine 2002;156(6):615-620.

13. Marlow N, Hennessy E, Bracewell M, Wolke D. Motor and executive function at 6 years of age following extremely preterm birth. Pediatrics 2007;120(4):793-804.

14. Wolke D, Meyer R. Cognitive status, language attainment, and prereading skills of 6year-old very preterm children and their peers: the Bavarian Longitudinal Study. Developmental Medicine and Child Neurology 1999;41:94-109.

15. Johnson A, Bowler U, Yudkin P, Hockley C, Wariyar U, Gardner F, et al. Health and school performance of teenagers born before 29 weeks gestation. Archives of Disease in Childhood Fetal Neonatal Edition 2003;88:F190-F198. 
16. Pinto-Martin J, Whitaker A, Feldman J, Cnaan A, Zhao H, Rosen-Bloch J, et al. Special education services and school performance in a regional cohort of low-birthweight infants at age nine. Paediatric and Perinatal Epidemiology 2004;18:120-129.

17. Buck GM, Msall ME, Schisterman EF, Lyon NR, T. RB. Extreme prematurity and school outcomes. Paediatric and Perinatal Epidemiology 2000;14:324-331.

18. Jennische M, Sedin G. School level at 10 years of age in children who required neonatal intensive care in 1980-1989. Acta Paediatrica 2006;95:1586-1593.

19. Saigal S, Hoult L, Streiner DL, Stoskopf BL, Rosenbaum P. School difficulties at adolescence in a regiional cohort of children who were extremely low birth weight. Pediatrics 2000;105(325-331).

20. Wocadlo C, Rieger I. Educational and therapeutic resource dependency at early school-age in children who were born very preterm. Early Human Development 2006;82:2937.

21. Costeloe K, Hennessy E, Gibson A, Marlow N, Wilkinson A. The EPICure Study: Outcomes to discharge from hospital for infants born at the threshold of viability. Pediatrics 2000;106(4):659-671.

22. Kaufman AS, Kaufman NL. Kaufman Assessment Battery for Children. Circle Pines, MN: American Guidance Service, Inc; 1983.

23. Wechsler D. Wechsler Individual Achievement Test, 2nd Edition UK: Harcourt Assessment Inc; 2004.

24. Flynn J. Searching for justice: the discovery of IQ gains over time. American Psychologist 1999;54:5-20.

25. Wolke D, Ratschinski G, Ohrt B, Riegel K. The cognitive outcome of very preterm infants may be poorer than often reported: an empirical investigation of how methodological issues make a big difference. European Journal of Pediatrics 1994;153:906-915.

26. Stigler JW, Lee S-Y, Stevenson HW. Mathematical knowledge of Japanese, Chinese and American Elementary school children. Reston, Virginia: The National Council of Teachers of Mathematics; 1990.

27. Wolke D, Leon-Villagra J. Mathematiktest fuer Grundschulkinder [Math test for elementary school children]. Munich: Bavarian Longitudinal Study; 1993.

28. Wolke D, Rizzo P, Woods S. Persistent infant crying and hyperactivity problems in middle childhood. Pediatrics 2002;109(6):1054-1060.

29. Office for National Statistics. The National Statistics Socio-Economic Classification User Manual.: Palgrave Macmillan; 2005.

30. Royston P. Update: Multiple imputation of missing values. . In: http://www.statajournal.com/software/sj5-4 accessed on 15th July 2008.

31. Taylor HG, Klein N, Minich N, Hack M. Middle school-age outcomes in children with very low birth-weight. Child Development 2000;71:1495-1511.

32. D'Angio CT, Sinkin RA, Stevens TP, Landfish NK, Merzbach JL, Ryan RM, et al. Longitudinal, 15-year follow-up of chidlren born at less than 29 weeks' gestation after introduction of surfactant therapy into a region: Neurologic, cognitive, and educational outcomes. Pediatrics 2002;110(6):1094-1102. 
33. Hack M, Taylor HG, Klein N, Eiben R, Schatschneider C, Mercuri-Minich N. Schoolage outcomes in children with birth weights under $750 \mathrm{~g}$. New England Journal of Medicine 1994;331(12):753-759.

34. Bhutta A, Cleves M, Casey P, Cradock M, Anand K. Cognitive and behavioral outcomes of school-aged children who were born preterm. A meta-analysis. Journal of the American Medical Association 2002;288(6):728-737.

35. Johnson S. Cognitive and behavioural outcomes following very preterm birth. Seminars In Fetal \& Neonatal Medicine 2007;12(5):363-373.

36. Wolke D, Schulz J, Meyer R. Entwicklungslanzeitfolgen bei ehemaligen, sehr unreifen Fruhgeborenen. Monatsschrift fur Kinderheilkunde 2001;(Suppl 1) 149:S53-S61.

37. Gross SJ, Slagle TA, D'Eugenio DB, Mettelman BB. Impact of a matched term control group on interpretation of developmental performance in preterm infants. Pediatrics 1992;90(5):681-687.

38. Hack M, Taylor HG, Klein N, Eiben R, Schatschneider C, Mercuriminich N. SchoolAge Outcomes In Children With Birth Weights Under 750 G. New England Journal Of Medicine 1994;331(12):753-759.

39. Inder TE, Warfield SK, Wang H, Huppi P, Volpe J. Abnormal cerebral structure is present at term in premature infants. Pediatrics 2005;115:286-294.

40. Kapellou O, Counsell SJ, Kennea N, Dyet L, Saeed N, Stark J, et al. Abnormal cortical development after premature birth shown by altered allometric scaling of brain growth. PLoS Medicine 2006;3(8):1382-1390.

41. Peterson BS, Vohr B, Staib LH, Cannistraci CJ, Dolberg A, Schneider KC, et al. Regional brain volume abnormalities and long-term cognitive outcome in preterm infants. Jama-Journal Of The American Medical Association 2000;284(15):1939-1947.

42. Gathercole SE, Pickering SJ, Knight C, Stegman Z. Working memory skills and educational attainment: Evidence from National Curriculum assessments at 7 and 14 years of age. Applied Cognitive Psychology 2004;18:1-16.

43. Bull R, Espy KA, Wiebe SA. Short-term memory, working memory, and executive functioning in preschoolers: longitudinal predictors of mathematical achievement at 7 years. Developmental Neuropsychology 2008;33(3):205-228.

44. Hille E, Ouden Ad, Saigal A, Wolke D, Lambert M, Whitaker A, et al. Behavioural problems in children who weight $1000 \mathrm{~g}$ or less at birth in four countries. Lancet 2001;357:1641-1643.

45. Samara M, Marlow N, Wolke D. Pervasive Behavior Problems at 6 Years of Age in a Total-Population Sample of Children Born at <25 Weeks of Gestation. Pediatrics 2008;122.

46. Department for Children Schools and Families. Special Educational Needs in England, January 2008: Office for National Statistics; 2008.

47. Johnson S, Fawke J, Hennessy E, Rowell V, Thomas S, Wolke D, et al. Neuordevelopmental disability through 11 years in extremely preterm: The EPICure Study. Submitted.

48. Sharp C, Hutchison D. How do season of birth and length of schooling affect children's attainment at Key Stage 1? A question revisited. Slough: NFER; 1997. 
49. Massey A, Elliott G, Ross E. Season of birth, sex and success in GCSE English, mathematics and science: some long-lasting effects from the early years? Research Papers in Education 1996;11(2):129-150.

50. Wood N, Marlow N, Costeloe K, Gibson A, Wilkinson A. Neurologic and developmental disability after extremely preterm birth. The New England Journal of Medicine 2000;343(6):378-384.

51. O'Brien F, Roth S, Stewart A, Rifkin L, Rushe T, Wyatt J. The neurodevelopmental progress of infants less than 33 weeks into adolescence. Archives Of Disease In Childhood 2004;89(3):207-211.

52. Petrou S, Henderson J, Bracewell M, Hockley C, Wolke D, Marlow N. Pushing the boundaries of viability: The economic impact of extreme preterm birth. Early Human Development 2006;82:77-84. 


\section{Acknowledgements}

This study was funded by the Medical Research Council. We are indebted to the EPICure Study Group, which includes paediatricians in 276 maternity units in the United Kingdom and Ireland who identified the original cohort, contributed data to the study and whose help was invaluable. We are also indebted to the schools and teachers who supported study assessments throughout this follow-up, and to the many children and parents for their continued participation in the EPICure Studies. We would also like to thank the pupils and staff of Sacred Heart RC Primary School, Westdale Junior School and Greythorn Primary School for their invaluable assistance in training.

Co-investigators were Neil Marlow (Nottingham; Chief Investigator), Kate Costeloe (London), Enid Hennessy (London), Janet Stocks (London) and Elizabeth Draper (Leicester). Study Progress was monitored by a steering group chaired by Peter Brocklehurst (Oxford). The 11 year Developmental Group also comprised Dieter Wolke (Warwick), Chris Hollis (Nottingham), Samantha Johnson (Nottingham), \& Richard Morton (Derby). Psychological assessments were performed by Rebecca Trikic, Rebecca Smith, \& Samantha Johnson. Heather Palmer was the Study Manager.

\section{Conflict of Interest}

None declared. All authors declare that the answer to the questions on your competing interest form are all No and therefore have nothing to declare. All researchers are independent of the funding body.

\section{Licence for publication}

The corresponding author has the right to grant on behalf of all authors and does grant on behalf of all authors, an exclusive licence on a worldwide basis to the BMJ Publishing Group Ltd and its Licensees to permit this article (if accepted) to be published in Archives of Disease in Childhood editions and any other BMJPGL products to exploit all subsidiary rights, as set out in the licence (http://adc.bmjjournals.com/ifora/licence.dtl). 


\section{What is already known on this topic}

- Very preterm children are at high risk for cognitive impairment and have poorer school performance than their term peers.

- Many children will enter school an academic year early due to preterm birth.

- The effect of early school entry on educational outcomes has not yet been investigated.

\section{What this study adds}

- Extremely preterm children are at high risk for learning difficulties and poor academic attainment at $\mathbf{1 1}$ years of age, particularly in mathematics.

- Almost two thirds of them require additional support in school.

- Children who enter school an academic year early due to extremely preterm birth have comparable academic attainment but require more special needs support.

\section{Website}

www.epicure.ac.uk 
Table 1. Mean (SD) scores for standardised tests of cognitive ability (K-ABC) and academic attainment (WIAT-II ${ }^{\mathrm{UK}}$ ) in extremely preterm children and classmates at 11 years.

\begin{tabular}{|c|c|c|c|c|c|c|c|}
\hline \multirow[t]{2}{*}{ Test } & \multicolumn{3}{|c|}{ Classmates } & \multicolumn{3}{|c|}{ Extremely preterm } & \multirow{2}{*}{$\begin{array}{c}\text { Mean difference } \\
(95 \% \mathrm{CI})\end{array}$} \\
\hline & $\mathbf{n}$ & Mean & (SD) & $\mathbf{n}$ & Mean & (SD) & \\
\hline K-ABC & 153 & 104.1 & (11.1) & 217 & 83.7 & 18.0 & $-20(-23$ to -17$)$ \\
\hline Simultaneous processing & 153 & 104.9 & $(11.9)$ & 201 & 86.7 & $(13.5)$ & $-18(-21$ to -15$)$ \\
\hline Sequential processing & 153 & 101.9 & $(11.5)$ & 201 & 91.5 & $(13.4)$ & $-10(-13$ to -8$)$ \\
\hline WIAT-II $^{\text {UK }}$ & 153 & 98.5 & (11.6) & 212 & 80.2 & (20.3) & $-18(-21$ to -15$)$ \\
\hline Word reading & 153 & 99.6 & $(12.1)$ & 199 & 86.3 & $(17.3)$ & $-13(-16$ to -10$)$ \\
\hline Reading comprehension & 153 & 100.6 & $(11.6)$ & 195 & 85.9 & $(18.3)$ & $-15(-18$ to -12$)$ \\
\hline Pseudoword decoding & 153 & 99.7 & $(11.3)$ & 199 & 68.7 & $(15.6$ & $-13(-16$ to -10$)$ \\
\hline \multirow{4}{*}{ Mathematical Reasoning } & 153 & 98.5 & (15.0) & 215 & 71.2 & (20.9) & $-27(-31$ to -24$)$ \\
\hline & 153 & 98.0 & $(15.5)$ & 199 & 75.6 & $(18.4)$ & $-22(-26$ to -19$)$ \\
\hline & 153 & 99.7 & $(12.0)$ & 198 & 78.2 & $(18.1)$ & $-21(-25$ to -18$)$ \\
\hline & 152 & 6.6 & (1.9) & 198 & 4.4 & $(2.0)$ & $-2.2(-1.7$ to -2.6$)$ \\
\hline
\end{tabular}


Table 2: Severity of cognitive and learning impairments in extremely preterm children and classmates at 11 years.

\begin{tabular}{|c|c|c|c|c|}
\hline \multirow[t]{2}{*}{ Domain of impaiment } & \multirow{2}{*}{$\begin{array}{c}\text { Classmates } \\
\text { All } \\
(n=153)\end{array}$} & \multicolumn{3}{|c|}{ Extremely preterm } \\
\hline & & Boys & Girls & All \\
\hline General cognitive ability & $(n=153)$ & $(n=101)$ & $(n=118)$ & $(n=219)$ \\
\hline No impairment & $129(84.3 \%)$ & $23(22.8 \%)$ & $46(39.0 \%)$ & $69(31.5 \%)$ \\
\hline Mild impaimment & $22(14.4 \%)$ & $28(27.7 \%)$ & $35(29.7 \%)$ & $63(28.8 \%)$ \\
\hline Moderate impaiment & $2(1.3 \%)$ & $27(26.7 \%)$ & $28(23.7 \%)$ & $55(25.1 \%)$ \\
\hline Severe impairment & $0(0.0 \%)$ & $23(22.8 \%)$ & $9(7.6 \%)$ & $32(14.6 \%)$ \\
\hline Reading & $(n=153)$ & $(n=97)$ & $(n=115)$ & $(n=212)$ \\
\hline No impaiment & $136(88.9 \%)$ & $40(41.2 \%)$ & $62(53.9 \%)$ & $102(48.1 \%)$ \\
\hline Mild impaiment & $14(9.2 \%)$ & $22(22.7 \%)$ & $24(20.9 \%)$ & $46(21.7 \%)$ \\
\hline Moderate impairment & $3(2.0 \%)$ & $10(10.3 \%)$ & $13(11.3 \%)$ & $23(10.8 \%)$ \\
\hline Severe impairment & $0(0.0 \%)$ & $25(25.8 \%)$ & $16(13.9 \%)$ & $41(19.3 \%)$ \\
\hline Maths & $(n=153)$ & $(n=99)$ & $(n=116)$ & $(n=215)$ \\
\hline No impaiment & $132(86.3 \%)$ & $29(29.3 \%)$ & $36(31.0 \%)$ & $65(30.2 \%)$ \\
\hline Mild impaiment & $19(12.4 \%)$ & $23(23.2 \%)$ & $33(28.4 \%)$ & $56(26.0 \%)$ \\
\hline Moderate impaiment & $2(1.3 \%)$ & $15(15.2 \%)$ & $27(23.3 \%)$ & $42(19.5 \%)$ \\
\hline Severe impairment & $0(0 \%)$ & $32(32.3 \%)$ & $20(17.2 \%)$ & $52(24.2 \%)$ \\
\hline
\end{tabular}

Impairment is classified relative to the Mean SD of classmates on each scale. No impairment $=$ scores $\geq-1 S D$, mild impairment $=$ scores -1 to $-2 \mathrm{SD}$, moderate impairment $=$ scores -2 to $-3 \mathrm{SD}$ and severe impairment $=$ scores $-3 \mathrm{SD}$. 
Table 3. Special educational needs (SEN) in extremely preterm children and classmates at 11 years.

\begin{tabular}{|c|c|c|c|c|c|}
\hline & \multicolumn{2}{|c|}{$\begin{array}{c}\text { Classmates } \\
(n=152)\end{array}$} & \multicolumn{2}{|c|}{$\begin{array}{l}\text { Extremely preterm } \\
\qquad(n=215)\end{array}$} & \multirow[t]{2}{*}{$\begin{array}{l}\text { Odds Ratio } \\
\text { (95\% CI) }\end{array}$} \\
\hline & $\mathbf{n}$ & $\%$ & $\mathbf{n}$ & $\%$ & \\
\hline Academic or behavioural SEN & 17 & $(11 \%)$ & 134 & $(62 \%)$ & $13.1(7.4$ to 23.3$)$ \\
\hline Boys & 12 & $(19 \%)$ & 76 & $(77 \%)$ & \\
\hline Girls & 5 & $(6 \%)$ & 58 & $(50 \%)$ & \\
\hline Risk for EP boys versus girls & & & & & $3.3(1.8$ to 6.0$)$ \\
\hline Utilises SEN resources $^{\dagger}$ & 17 & $(11 \%)$ & 132 & $(61 \%)$ & $12.6(7.1$ to 22.4$)$ \\
\hline Boys & 11 & $(17 \%)$ & 73 & $(74 \%)$ & \\
\hline Girls & 6 & $(6.8)$ & 59 & $(51 \%)$ & \\
\hline Risk for EP boys versus girls & & & & & $2.7(1.5$ to 4.8$)$ \\
\hline Educational Statement* & 1 & $(0.7 \%)$ & 72 & $(34 \%)$ & 77 (10.6 to 562$)$ \\
\hline Boys & 1 & $(1.6 \%)$ & 43 & $(44 \%)$ & \\
\hline Girls & 0 & $(0 \%)$ & 29 & $(25 \%)$ & \\
\hline Risk for EP boys versus girls & & & & & $2.4(1.3$ to 4.3$)$ \\
\hline
\end{tabular}

\section{MAINSTREAM SCHOOLS ONLY}

\begin{tabular}{|c|c|c|c|c|c|}
\hline \multirow[b]{2}{*}{ Academic or behavioural SEN } & \multicolumn{2}{|c|}{$(n=152)$} & \multicolumn{2}{|c|}{$(n=186)$} & \multirow[b]{2}{*}{$10.3(5.8$ to 18.4$)$} \\
\hline & 17 & $(11 \%)$ & 105 & $(57 \%)$ & \\
\hline Boys & 12 & $(19 \%)$ & 55 & $(71 \%)$ & \\
\hline Girls & 5 & $(6 \%)$ & 50 & $(46 \%)$ & \\
\hline Risk for EP boys versus girls & & & & & $2.8(1.5$ to 5.1$)$ \\
\hline Utilises SEN resources & 17 & $(11 \%)$ & 103 & $(55 \%)$ & $9.9(5.5$ to 17.6$)$ \\
\hline Boys & 11 & $(17 \%)$ & 52 & $(67 \%)$ & \\
\hline Girls & 6 & (7) & 51 & $(47 \%)$ & \\
\hline Risk for EP boys versus girls & & & & & $2.2(1.2$ to 4.1$)$ \\
\hline Educational Statement* & 1 & $(0.7 \%)$ & 43 & $(23 \%)$ & $46(6.3$ to 339$)$ \\
\hline Boys & 1 & $(1.6 \%)$ & 22 & $(29 \%)$ & \\
\hline Girls & 0 & $(0 \%)$ & 21 & $(19 \%)$ & \\
\hline Risk for EP boys versus girls & & & & & $1.7(0.8$ to 3.4$)$ \\
\hline
\end{tabular}

${ }^{+}$SEN provision refers to the number of children utilising at least one SEN resource (listed in Figure 1). * Data for the prevalence of educational statements excludes children in Ireland. 
Table 4. Educational outcomes for extremely preterm children in mainstream schools who were entered in the appropriate school year $(n=122)$ compared with those that would have been entered for a school a year earlier than if they were born at term $(n=68)$.

\begin{tabular}{|c|c|c|c|c|c|c|c|}
\hline & \multicolumn{3}{|c|}{ Appropriate school entry } & \multicolumn{3}{|c|}{ Early school entry } & \multirow{2}{*}{$\begin{array}{c}\text { Mean difference } \\
(95 \% \mathrm{CI})\end{array}$} \\
\hline & $\mathbf{n}$ & Mean & (SD) & $\mathbf{n}$ & Mean & (SD) & \\
\hline K-ABC: MPC & 122 & 88.9 & 12.3 & 66 & 87.2 & 15.0 & $-1.7(-5.7$ to 2.3$)$ \\
\hline WIAT-II UK: Reading & 122 & 84.9 & 15.4 & 65 & 84.5 & 18.3 & $-0.3(-5.3$ to 4.6$)$ \\
\hline WIAT-II ${ }^{\mathrm{UK}}$ : Maths & 122 & 75.9 & 18.1 & 65 & 74.4 & 20.4 & $-1.5(-7.3$ to 4.2$)$ \\
\hline Maths estimation & 121 & 4.7 & 1.9 & 63 & 4.6 & 2.1 & $-0.1(-0.7$ to 0.5$)$ \\
\hline & & $\mathbf{n}$ & $\%$ & & $\mathbf{n}$ & $\%$ & OR (95\% CI) \\
\hline Cognitive impairment & & 37 & $(30 \%)$ & & 22 & $(32 \%)$ & $1.1(0.6$ to 2.1$)$ \\
\hline Impairment in reading & & 25 & $(21 \%)$ & & 16 & $(25 \%)$ & $1.3(0.6$ to 2.6$)$ \\
\hline Impairment in maths & & 40 & $(33 \%)$ & & 26 & $(40 \%)$ & $1.4(0.7$ to 2.6$)$ \\
\hline$<$ average attainment (teacher) & & 46 & $(46 \%)$ & & 31 & $(56 \%)$ & $1.5(0.8$ to 2.9$)$ \\
\hline Academic / behavioural SEN & & 60 & $(50 \%)$ & & 45 & $(67 \%)$ & $2.0(1.1$ to 3.8$)$ \\
\hline Utilises SEN resources & & 59 & $(50 \%)$ & & 44 & $(66 \%)$ & $1.9(1.0$ to 3.6$)$ \\
\hline Educational statement & & 21 & $(18 \%)$ & & 22 & $(33 \%)$ & $2.3(1.2$ to 4.6$)$ \\
\hline
\end{tabular}

K-ABC and WIAT-II ${ }^{\mathrm{UK}}$ scales yield standardised scores with Mean 100, SD 15. Scores for maths estimation range 0 to 11 . Impairment refers to serious impairment (moderate and severe impairment combined). Teacher rated academic attainment refers to total TAAS scores used to classify overall attainment below the national age-expected average. Data for educational statements exclude children in Ireland. 


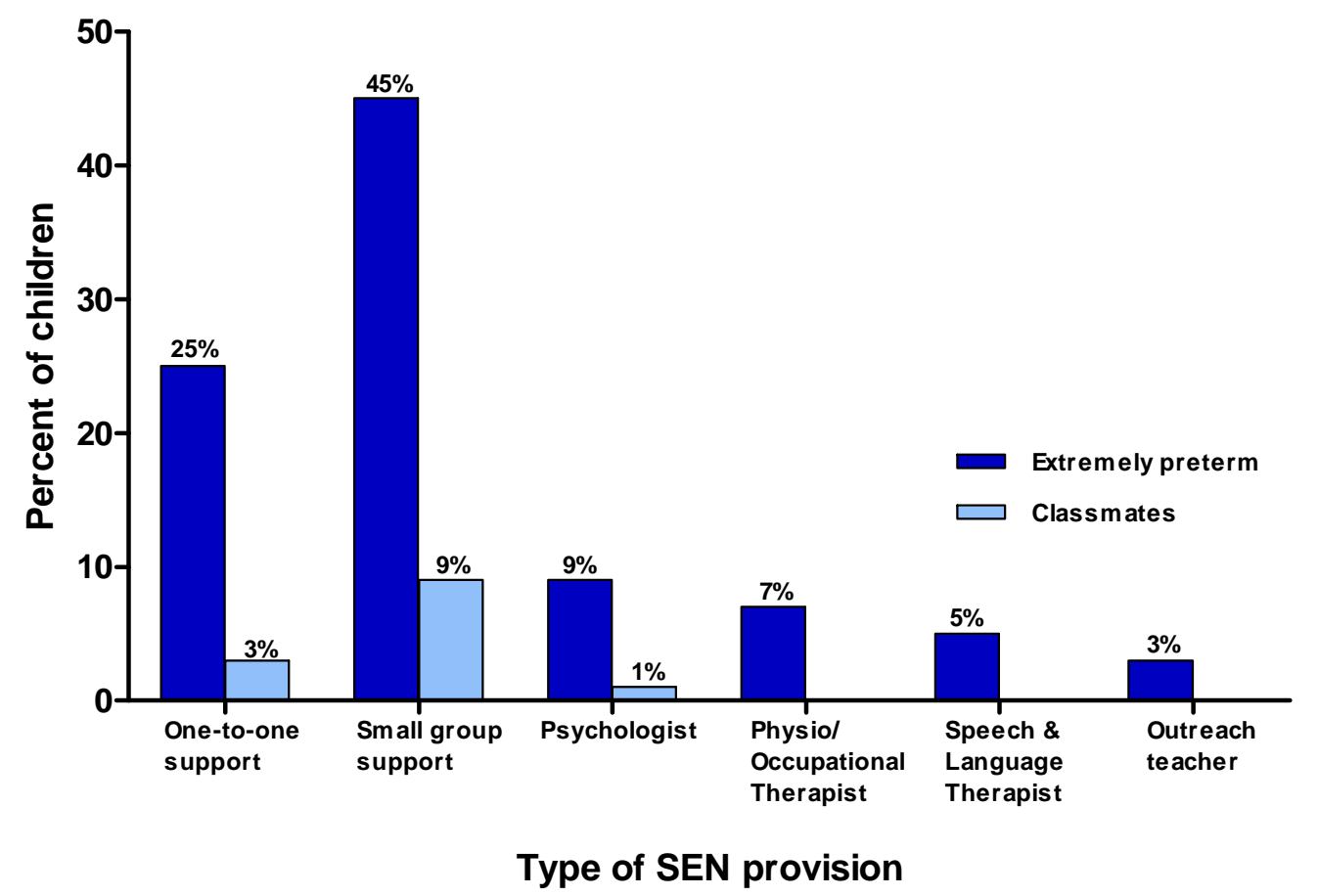

Figure 1. Type of special educational needs (SEN) resources utilised by extremely preterm children and classmates in mainstream schools at 11 years of age. 
Table s1. Differences between extremely preterm children assessed and not assessed at 11 years.

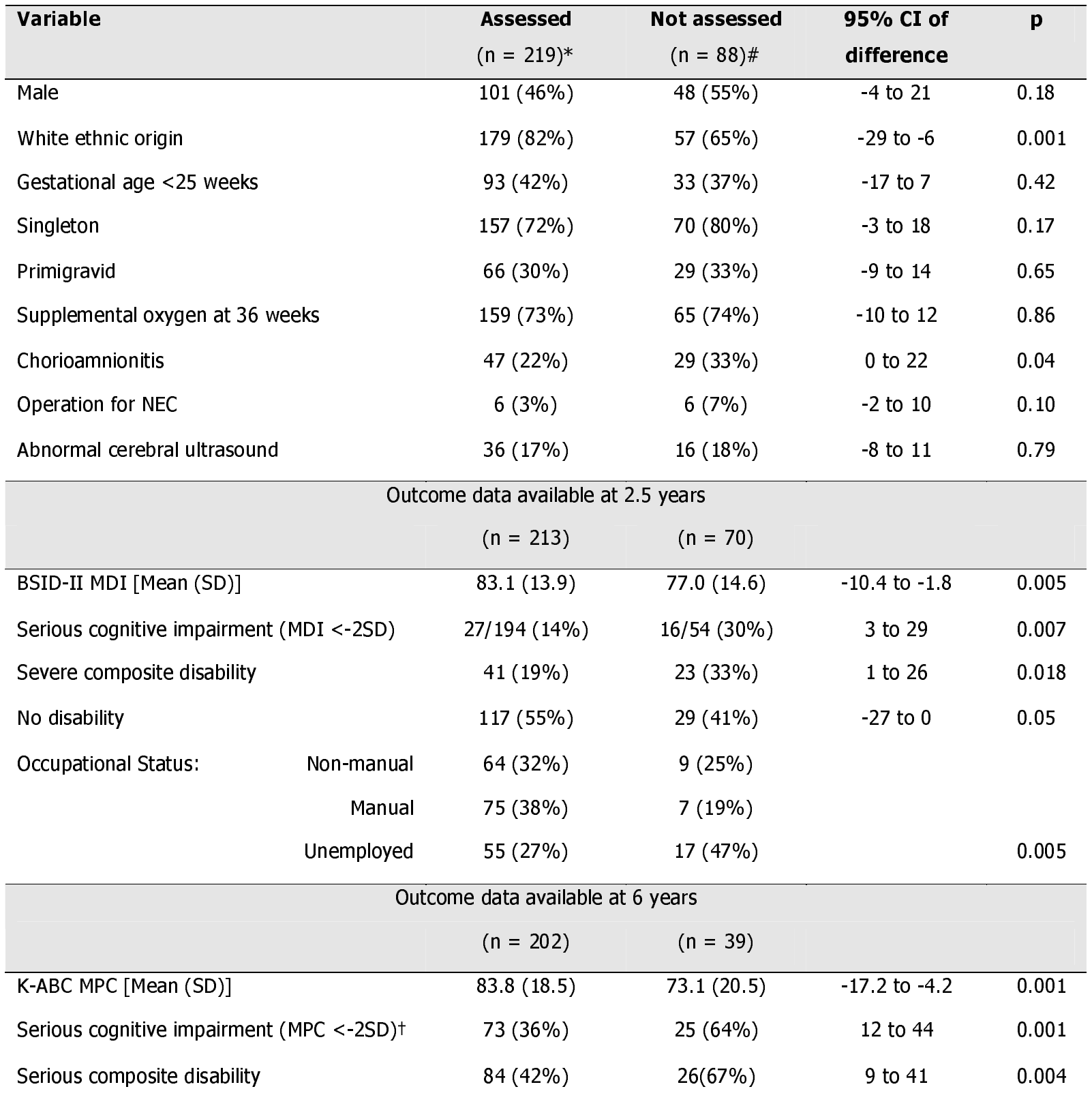

* $n=219$ for sex and gestational age, $n=218$ for remaining variables as one child was initially identified at the 11-year follow-up. \# n=88 excluding two children who died between the 6 -year and 11-year follow-up. + Serious cognitive impairment at 6 years is classified according to the Mean (SD) of the comparison group. BSID-II MDI = Bayley Scales of Infant Development, 2nd Edition, Mental Development Index. K-ABC MPC = Kaufman Assessment Battery for Children, $1^{\text {st }}$ Edition, Mental Processing Composite. 


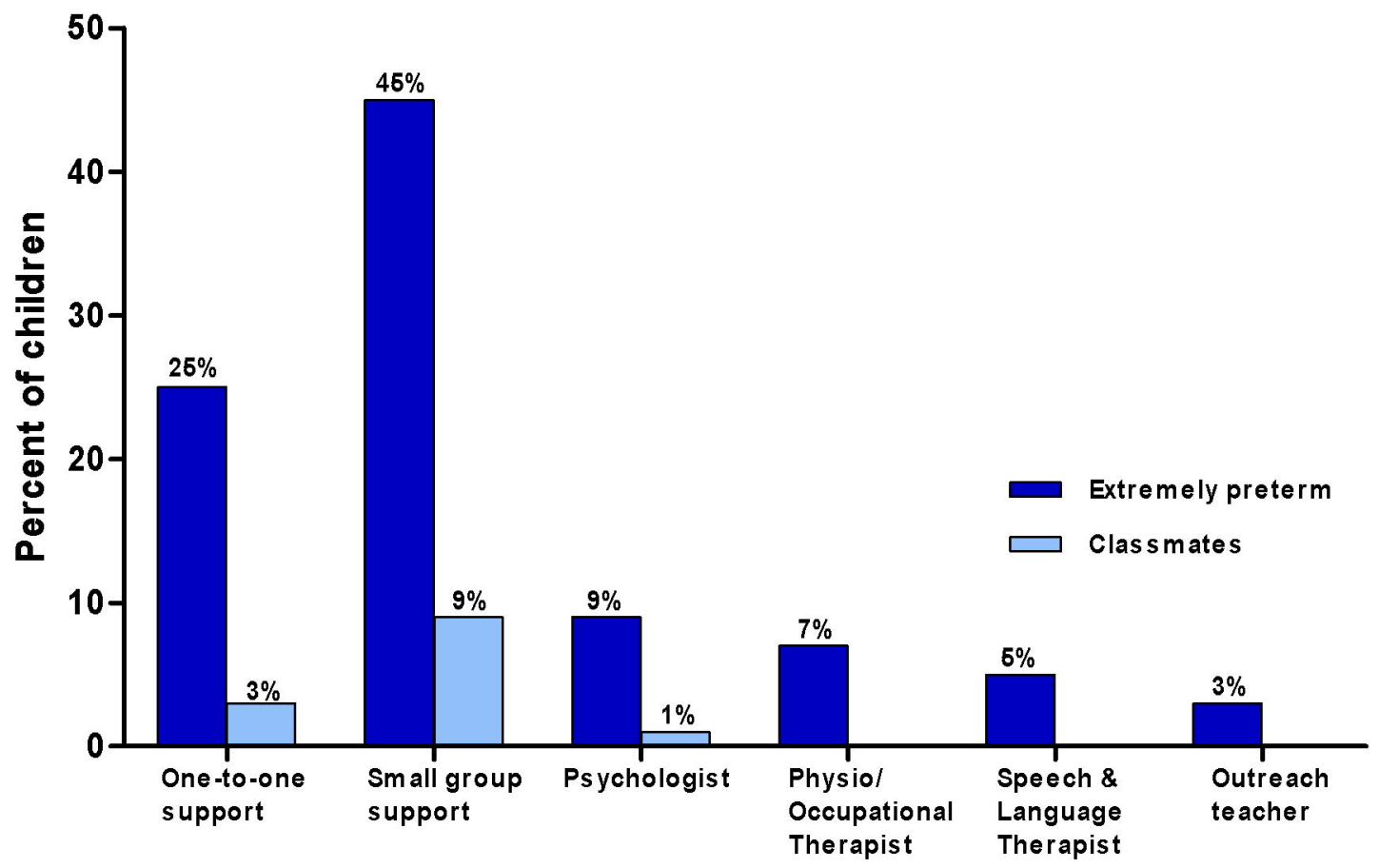

